\title{
A randomized, double-blind, placebo-controlled study of oral antioxidant supplement therapy in patients with dry eye syndrome
}

This article was published in the following Dove Press journal:

Clinical Ophthalmology

9 May 2016

Number of times this article has been viewed

\section{Jehn-Yu Huang \\ Po-Ting Yeh \\ Yu-Chih Hou}

Department of Ophthalmology, National Taiwan University Hospital, College of Medicine, National Taiwan University, Taipei, Taiwan
Correspondence: Yu-Chih Hou Department of Ophthalmology, National Taiwan University Hospital, College of Medicine, National Taiwan University, 7, Chung-Shan South Road, Taipei I0002,

Taiwan

Tel +886223123456 ext 65205

Fax +886223412875

Email ychou5I@ntu.edu.tw
Purpose: To evaluate the efficacy of oral antioxidant supplementation in the treatment of patients with dry eye syndrome (DES).

Methods: A prospective, randomized, double-blinded study compared the effects of an antioxidant supplement (containing anthocyanosides, astaxanthin, vitamins A, C, and E, and several herbal extracts, including Cassiae semen and Ophiopogonis japonicus) with placebo on patients with DES. We assessed dry eye symptoms, visual acuity, Schirmer's test, tear film breakup time, cornea and conjunctiva fluorescein staining, serum anti-SSA/anti-SSB antibodies, and the level of reactive oxygen species (ROS) in tears. The supplementation period was 8 weeks and patients were followed up every 4 weeks for 16 weeks. A linear mixed model was used to compare the groups, while within-group differences were tested by repeated-measures analysis of variance.

Results: Forty-three patients, 20 and 23 in treatment and placebo groups, respectively, completed the study. Liver and renal functions were normal. Diastolic blood pressure decreased in the treatment group. There were no significant differences in systolic blood pressure, dry eye symptoms, serum anti-SSA and anti-SSB, visual acuity, intraocular pressure, or fluorescein corneal staining between the groups. Tear film breakup time scores and Schirmer's test without topical anesthesia significantly improved in the treatment group. Tear ROS level differed between the groups and decreased after treatment. Overall subjective impression revealed a significant improvement with treatment compared with placebo.

Conclusion: Oral antioxidant supplementations may increase tear production and improve tear film stability by reducing tear ROS. The vegetable-based antioxidant supplement used in this study is safe and can be utilized as an adjuvant therapy to conventional artificial tear therapy for patients with DES.

Keywords: dry eye, tear, reactive oxygen species, blood pressure, herbal extracts

\section{Introduction}

Dry eye syndrome (DES) is a disorder of tear deficiency or excessive tear evaporation resulting in an unstable tear film. Typical symptoms comprise dryness, burning sensation, visual disturbance, and sandy-gritty eye irritation. Dry eye is associated with chronic inflammation in the functional unit of the lacrimal gland-ocular surface and can damage the ocular surface. The prevalence of DES increases with age and affects approximately one-third of the elderly population. ${ }^{1,2}$ Traditional treatments for DES are supplementation of artificial tears or punctal occlusion, in order to increase the volume of the tear film or reduce drainage. ${ }^{3}$ However, artificial tear substitutes can only temporarily relieve dry eye discomfort. Inflammation has been shown to play a 
role in DES; therefore, anti-inflammation medications, such as short-term steroids or long-term cyclosporine $\mathrm{A}$, have demonstrated promising results. ${ }^{3-5}$

Dietary nutrients have been shown to be involved in the pathogenesis of DES. ${ }^{6,7}$ Essential fatty acids play a role in the inflammation process. $^{8}$ Systemic omega-3 can mediate inflammation and has been used to treat DES, particularly in cases associated with meibomian gland dysfunction. ${ }^{9,10}$ Oral antioxidants, such as vitamin A or multivitamins, can improve tear film stability and the health of the conjunctival surface. ${ }^{11,12}$ Free radicals can attack the cellular plasma membrane and cause cell damage and death. ${ }^{13}$ They can also damage the epithelial tissues of the conjunctiva, the lacrimal glands, and tear-secreting tissues. Exposure to ozone can degrade tear proteins and cause chronic dysfunction of the tear film. ${ }^{14}$ Antioxidants can protect against free radicals and may help conjunctival tissues in the provision of a stable tear film. ${ }^{15}$

In this study, we evaluated the efficacy of an oral antioxidant supplement (a combined formula of antioxidants and crude extracted additives from several herbal plants) in the treatment of DES, compared with placebo. We also evaluated the activity of its antioxidants by measuring reactive oxygen species (ROS) in tears.

\section{Patients and methods}

This prospective, randomized, double-blinded study was performed at the National Taiwan University Hospital, and the study protocol (ID: 201101005MA) was approved by the Institutional Review Board of the National Taiwan University Hospital. The study was conducted in accordance with the tenets of the Declaration of Helsinki. After obtaining written informed consent from patients and clinical screening, patients with DES were enrolled in the study and randomized into either the treatment or placebo group.

\section{Experimental supplements}

For the oral antioxidant group, we administered a commercially available antioxidant supplement containing anthocyanosides, astaxanthin, vitamins A, C, and E, and crude extracted additives from several Chinese herbal extracts (including Cassiae semen and Ophiopogonis japonicus) in the form of caplet (Acrobio Healthcare Inc., Taichung, Taiwan). These herbal extracts possessed some anti-inflammatory properties. The composition of caplets is shown in Table 1. For the placebo group, we created a placebo supplement containing starch with natural food coloring; it did not contain any antioxidants.
Table I Oral antioxidant supplement caplet composition

\begin{tabular}{ll}
\hline Component & Weight $\mathbf{( m g )}$ \\
\hline Lycii fructus extract (I0:I) & 200 \\
Astaxanthin (I0\%) & 20 \\
Bilberry extract (40\% anthocyanosides) & 120 \\
Vitamin A I,500 IU & 3 \\
Vitamin C & 50 \\
Vitamin E (50\%) & 30 \\
Selenium yeast (0.22\%) & 5 \\
Zinc gluconate (I2.5\%) & 10 \\
Vitamin B complex & 3 \\
Herbal food additives (Cassiae semen, & 200 \\
Ophiopogonis japonicus) & \\
Starch and magnesium stearate & 274 \\
\hline
\end{tabular}

\section{Experimental design}

This study was a double-blinded, randomized, parallelgroup, and placebo-controlled trial aimed to evaluate the efficacy and safety of an oral antioxidant supplement in the treatment of DES. Patient inclusion criteria comprised: age above 20 years and below 75 years and at least two of the following five symptoms: burning sensation, dry eye sensation, itching, pain, or foreign body sensation. Also, they were required to meet one of the following criteria in at least two examinations: basal Schirmer's test values $<5 \mathrm{~mm}$ at 5 minutes after topical $0.5 \%$ proparacaine anesthesia, tear film breakup time (TFBUT) $<10$ seconds, or positive corneal fluorescein staining. The exclusion criteria comprised ocular trauma within the 4 weeks prior to screening, previous ocular surgery, nasolacrimal obstruction, known hypersensitivity to traditional Chinese herbal or any other ingredient in the formula, pregnancy, lactation, and use of oral contraceptive drugs. During the study period, the intake of the following drugs or health food supplements was forbidden: any formula containing supplements of lutein, zeaxanthin, vitamin A, or omega-3; topical azithromycin; steroids; cyclosporine A; pilocarpine eye drops; tetracycline ointment; oral tetracycline; doxycycline; and androgen supplements. All patients took ordinary diet as usual and did not change it much during this trial period.

After undergoing screening at an outpatient clinic, all enrolled patients entered a washout period for 2 weeks. During washout and supplementation periods, artelac $(0.32 \%$ hypromellose; Bausch \& Lomb Incorporated, Bridgewater, NJ, USA) was administered four times daily or the patients' previously prescribed artificial tears were continued. Each patient received a caplet of the supplement or placebo twice daily for 8 weeks. Patients were followed up for an additional 8 weeks after discontinuing supplementation. Patients were followed up every 4 weeks for 16 weeks. They received regular physical and ocular examinations, and laboratory 
testing of ROS levels in tears was performed at every visit. Physical examinations included blood pressure of the right arm, heart rate, and body temperature. Ocular examinations included best-corrected visual acuity (BCVA), intraocular pressure (IOP), slit-lamp biomicroscopy, fluorescein staining, TFBUT, and Schirmer's tests with and without $0.5 \%$ proparacaine anesthesia. Blood tests, including complete blood cell count, liver transaminases, creatinine, and serum value of anti-SSA and anti-SSB antibodies, were performed just before the initiation of treatment, at the end of the 8-week treatment period, and at the end of the 16-week study.

\section{ROS measurements by luminol- dependent chemiluminescence assay}

Tears were collected by cellulose acetate filter paper from Schirmer's test and immediately stored in liquid nitrogen after Schirmer's test for ROS measurement. ROS formation was measured by a chemiluminescence assay using luminol (5-amino-2,3-dihydro-1,4-phthalazinedione). The luminometer measured chemiluminescence after luminol was added. ROS production of tear samples was counted in a dark chamber of the chemiluminescence analyzing system (CLD-FS1; Tohoku Electronic Industrial Co., Sendai, Japan). The total amount of chemiluminescence was calculated by integrating the area under the curve and subtracting it from the background level. Samples were assayed, and the output was expressed as chemiluminescence counts/10 seconds for samples in luminol. Negative results of chemiluminescence counts were labeled zero and indicated no response. The output of each sample was divided by the total length (millimeters) of cellulose acetate filter paper containing tears, for further comparison of the severity of ROS-induced oxidative stress in samples.

Subjective evaluation included the following five symptoms: burning sensation, dry eye sensation, foreign body sensation, itching, and pain. The severity of these symptoms was scored according to four levels: 0 (none), 1 (mild), 2 (moderate), and 3 (severe). Objective evaluation included Schirmer's tests with and without $0.5 \%$ proparacaine anesthesia, BCVA, IOP, TFBUT, and ocular surface examination by biomicroscopy. An overall impression for the treatment effect was also evaluated at the end of the study. Records of ocular surface presentation included discharge, foamy tears, conjunctival redness, and fluorescein staining of the conjunctiva and cornea. The severity of these parameters was also scored according to four levels: 0 (none), 1 (mild), 2 (moderate), and 3 (severe). Biomicroscopic examinations and the evaluation of these parameters were all performed by Dr Hou at each visit. Subjective evaluation and measurements of BCVA, IOP, and blood pressure were performed by clinical technicians. Tear ROS measurements were performed by laboratory technicians. These different observations were all in masked fashion.

\section{Sample size estimation}

Because there was no similar study to evaluate the effect of the same antioxidant in dry eye management, we assumed that the results of Schirmer's test would be improved after treatment with 8-week oral antioxidant supplement. We proposed a sample size of 23 eyes from 23 subjects in each group will have $80 \%$ power to detect a difference of $1.5 \mathrm{~mm} / 5$ minutes in Schirmer's test and by assuming a common standard deviation of $2.0 \mathrm{~mm} / 5$ minutes using a two group $t$-test at a one-sided significance level of 0.05 . By assuming a $20 \%$ dropout rate, we planned to recruit 28 patients in each group in our study.

\section{Statistical analysis}

Statistical analysis was performed using Statistical Package for the Social Sciences for Windows Version 19.0 (IBM Corporation, Armonk, NY, USA). Measurements of both eyes from the same individual were included for data analysis. Since the measurements obtained from the right and left eyes of a patient are often correlated, a linear mixed model was used to determine significant differences in scale variables between groups. Within-group differences, before and after treatment, in scale variables were tested by repeated-measures analysis of variance. If there was a significant difference, post hoc analysis was performed using the Bonferroni method. Since the serum values of anti-SSA and anti-SSB antibodies did not follow a normal distribution, intergroup differences of these parameters were analyzed by Mann-Whitney $U$-test. For categorical variables, the chi-square test was used. A $P$-value $<0.05$ was considered to be statistically significant.

\section{Primary endpoint}

The primary aim of this study was to evaluate the efficacy of this antioxidant supplement in dry eye patients compared with placebo. Therefore, the primary endpoints were improvement of TFBUT and Schirmer's test at week 8.

\section{Secondary efficacy endpoint}

The secondary efficacy endpoints were to evaluate the changes in physical examinations, the results of blood tests, and the level of ROS in tears, subjective symptoms, and objective signs including severity scores of slit-lamp microscopy, conjunctival and corneal fluorescein staining 
before treatment, during treatment, and after the discontinuous treatment.

\section{Results}

A total of 66 patients were enrolled in this study and 43 of these completed the study, comprising 20 patients in the treatment group and 23 patients in the placebo group. The reasons for discontinuation were personal or family wish (16 patients), protocol deviation (five patients), and the occurrence of adverse events (two patients). Of the two cases of adverse events, one patient presented symptoms of gastritis and the other had unrelated acute tonsillitis after upper respiratory infection. Due to the significant dropout rate in both groups, a per-protocol analysis was used to evaluate the efficacy of oral antioxidant supplementation in this study.

At baseline, there were no differences in demographic data and measurement parameters between the treatment and placebo groups. There were no significant differences of severity grading of the dry eye at baseline between the two groups. The mean patient age was $58.09 \pm 10.5$ years in the placebo group and $62.2 \pm 8.9$ years in the treatment group ( $P=0.177$, independent $t$-test). There was no significant difference in sex distribution between the two groups (ten men and 13 women in the placebo group, seven men and 13 women in the treatment group; $P=0.571$ ). The blood cell results showed no difference between the two groups in relation to white blood cells, red blood cells, platelets, and the hemogram (data not shown). The liver transaminases and blood creatinine levels were normal and did not change after supplementation treatment in both groups. There were no differences in body weight or temperature between the two groups and no changes between before and after treatment (data not shown). Blood pressure measurements did not reveal any differences in systolic pressure between the groups; however, a significant reduction in diastolic pressure was recorded in the treatment group at visit 2 (Tables 2 and 3 ).

Table 2 Systolic blood pressure $(\mathrm{mmHg})$ given as mean \pm standard deviation

\begin{tabular}{|c|c|c|c|}
\hline Visit & $\begin{array}{l}\text { Placebo } \\
\text { group }\end{array}$ & $\begin{array}{l}\text { Treatment } \\
\text { group }\end{array}$ & $P_{\text {-value }}{ }^{a}$ \\
\hline Visit I (day 0) & $134.8 \pm 23.5$ & $130.6 \pm 15.3$ & 0.500 \\
\hline Visit 2 (week 4) & $129.5 \pm 24.3$ & $125.5 \pm \mid 4.9$ & 0.365 \\
\hline Visit 3 (week 8) & $126.0 \pm 21.5$ & $122.7 \pm 15.6$ & 0.569 \\
\hline Visit 4 (week I2) & $129.2 \pm 20.8$ & $129.9 \pm 18.5$ & 0.897 \\
\hline Visit 5 (week 16) & $133.3 \pm 23.2$ & $126.1 \pm 16.6$ & 0.250 \\
\hline$P$-value ${ }^{b}$ & 0.659 & 0.615 & \\
\hline
\end{tabular}

Notes: andependent $t$-test; ${ }^{b}$ repeated-measures analysis of variance.
Table 3 Diastolic blood pressure $(\mathrm{mmHg})$ given as mean \pm standard deviation

\begin{tabular}{llll}
\hline Visit & $\begin{array}{l}\text { Placebo } \\
\text { group }\end{array}$ & $\begin{array}{l}\text { Treatment } \\
\text { group }\end{array}$ & P-value $^{\mathbf{a}}$ \\
\hline Visit I (day 0) & $78.5 \pm 12.6$ & $78.9 \pm 13.7$ & 0.92 I \\
Visit 2 (week 4) & $79.6 \pm 12.9$ & $73.3 \pm 5.1$ & 0.032 \\
Visit 3 (week 8) & $76.8 \pm 11.3$ & $73.8 \pm 11.2$ & 0.399 \\
Visit 4 (week 12) & $76.7 \pm 12.2$ & $76.0 \pm 10.3$ & $0.85 \mathrm{I}$ \\
Visit 5 (week 16) $^{\text {P-value }}$ & $79.2 \pm 14.1$ & $75.5 \pm 15.7$ & 0.443 \\
\hline
\end{tabular}

Notes: andependent $t$-test; ${ }^{b}$ repeated-measures analysis of variance.

Although there were no significant differences at visit 3, the mean diastolic pressure was relatively reduced in the treatment group. There was no significant difference in heart rate between the groups.

The BCVA (logarithm of the minimum angle of resolution) and IOP did not significantly change before and after treatment in both groups (data not shown). In the scores of the five subjective symptoms (burning sensation, dry eye sensation, itching, pain, and foreign body sensation), there were no significant differences between the two groups. Schirmer's test without topical anesthesia was significantly different between the treatment group and the placebo group at 8 weeks of supplementation $(7.79 \pm 4.50$ vs $5.72 \pm 3.80$ $\mathrm{mm} / 5$ minutes, $P=0.027$ ) (Table 4 ); however, there was no difference in Schirmer's test under topical 0.5\% proparacaine anesthesia between the two groups (Table 5). There were no significant differences in the clinical assessments of discharge, foamy tears, conjunctival redness, and fluorescein staining of the conjunctiva and cornea between the two groups; however, corneal fluorescein staining improved after 2 months of supplementation (Table 6). With regard to TFBUT scores, significant differences were observed between the two groups at 4 weeks after supplementation; the scores showed significant improvement after treatment in the treatment group, but not in the placebo group (Table 7).

Table 4 Schirmer's test without $0.5 \%$ proparacaine anesthesia ( $\mathrm{mm} / 5$ minutes) given as mean \pm standard deviation

\begin{tabular}{llll}
\hline Visit & $\begin{array}{l}\text { Placebo } \\
\text { group }\end{array}$ & $\begin{array}{l}\text { Treatment } \\
\text { group }\end{array}$ & P-value $^{\text {a }}$ \\
\hline Visit I (day 0) & $7.1 \mathrm{I} \pm 5.64$ & $6.58 \pm 4.8 \mathrm{I}$ & 0.638 \\
Visit 2 (week 4) & $8.00 \pm 6.42$ & $7.63 \pm 5.56$ & 0.772 \\
Visit 3 (week 8) & $5.72 \pm 3.80$ & $7.79 \pm 4.50$ & 0.027 \\
Visit 4 (week 12) & $6.48 \pm 5.52$ & $7.95 \pm 7.32$ & 0.302 \\
Visit 5 (week 16) & $7.13 \pm 4.43$ & $8.60 \pm 5.42$ & 0.177 \\
P-value & 0.487 & 0.729 & \\
\hline
\end{tabular}

Notes: a Linear mixed model; ${ }^{\mathrm{b}}$ repeated-measures analysis of variance. 
Table 5 Schirmer's test with $0.5 \%$ proparacaine anesthesia ( $\mathrm{mm} / 5$ minutes) given as mean \pm standard deviation

\begin{tabular}{llll}
\hline Visit & $\begin{array}{l}\text { Placebo } \\
\text { group }\end{array}$ & $\begin{array}{l}\text { Treatment } \\
\text { group }\end{array}$ & P-value $^{\text {a }}$ \\
\hline Visit I (day 0) & $3.70 \pm 3.66$ & $3.35 \pm 2.64$ & 0.614 \\
Visit 2 (week 4) & $3.61 \pm 2.11$ & $3.43 \pm 2.39$ & 0.708 \\
Visit 3 (week 8) & $3.13 \pm 2.00$ & $3.82 \pm 2.79$ & 0.209 \\
Visit 4 (week I2) & $3.50 \pm 2.38$ & $3.60 \pm 2.93$ & 0.864 \\
Visit 5 (week 16) $^{\text {P-value }}$ & $3.91 \pm 2.83$ & $3.60 \pm 2.57$ & 0.592 \\
\hline
\end{tabular}

Notes: aLinear mixed model; ${ }^{b}$ repeated-measures analysis of variance.

The levels of ROS in the tears without topical anesthesia significantly reduced after 8 weeks of treatment in the treatment group, but not in the placebo group (Table 8). The levels of tear ROS in the treatment group reduced after treatment and increased after the treatment was discontinued. The levels of ROS in the tears under $0.5 \%$ proparacaine anesthesia showed a significant difference between the two groups at 8 weeks of supplementation (Table 9). Although the mean values of serum anti-SSA and anti-SSB antibodies decreased after treatment and increased after the treatment was discontinued in the treatment group, this was not statistically significant (Table 10). The overall subjective impression for treatment effect revealed a significant improvement in the treatment group compared with the placebo group (Table 11).

\section{Discussion}

DES is a multifactorial tear and ocular surface disease associated with increased osmolality of the tear film and inflammation of the ocular surface. The Dry Eye Workshop demonstrated that the pathophysiology of DES was associated with an inflammatory mechanism. ${ }^{4}$ Inflammation may cause dysfunction in the cells responsible for tear secretion or retention and leads to ocular surface disease. Artificial tears

Table 6 Severity of corneal fluorescein staining given as mean \pm standard deviation

\begin{tabular}{llll}
\hline Visit & $\begin{array}{l}\text { Placebo } \\
\text { group }\end{array}$ & $\begin{array}{l}\text { Treatment } \\
\text { group }\end{array}$ & P-value $^{\text {a }}$ \\
\hline Visit I (day 0) & $1.61 \pm 0.86$ & $1.23 \pm 0.77$ & 0.031 \\
Visit 2 (week 4) & $1.33 \pm 0.99$ & $1.15 \pm 0.80$ & 0.365 \\
Visit 3 (week 8) & $1.00 \pm 0.99$ & $0.88 \pm 0.85$ & 0.531 \\
Visit 4 (week 12) & $1.22 \pm 1.03$ & $1.15 \pm 0.92$ & 0.750 \\
Visit 5 (week 16) $^{\text {P-value }}$ & $1.48 \pm 1.00$ & $1.55 \pm 1.01$ & 0.743 \\
\hline
\end{tabular}

Notes: Severity is graded as 0 , no staining; I, mild; 2 , moderate; 3 , severe. ${ }^{\text {LLinear }}$ mixed model; ' brepeated-measures analysis of variance. *Post hoc analysis (Bonferroni method) showed a significant difference between visit I and visit $3(P=0.03 I)$. **Post hoc analysis (Bonferroni method) showed a significant difference between visit 3 and visit $5(P=0.007)$.
Table 7 Tear film breakup time (seconds) given as mean \pm standard deviation

\begin{tabular}{llll}
\hline Visit & $\begin{array}{l}\text { Placebo } \\
\text { group }\end{array}$ & $\begin{array}{l}\text { Treatment } \\
\text { group }\end{array}$ & P-value $^{\mathbf{a}}$ \\
\hline Visit I (day 0) & $3.22 \pm 2.09$ & $3.80 \pm 2.27$ & $0.22 \mathrm{I}$ \\
Visit 2 (week 4) & $3.4 \mathrm{I} \pm \mathrm{I} .6 \mathrm{I}$ & $4.70 \pm 2.68$ & 0.010 \\
Visit 3 (week 8) & $4.00 \pm 2.06$ & $4.33 \pm 2.06$ & 0.467 \\
Visit 4 (week 12) & $3.46 \pm 1.76$ & $3.38 \pm 1.68$ & 0.827 \\
Visit 5 (week I6) $^{\text {P-value }}$ & $3.30 \pm 2.06$ & $2.53 \pm 1.30$ & 0.037 \\
\hline
\end{tabular}

Notes: ainear mixed model; brepeated-measures analysis of variance. *Post hoc analysis (Bonferroni method) showed a significant difference between visit 2 and visit $4(P=0.043)$, visit 2 and visit $5(P<0.001)$, and visit 3 and visit $5(P=0.001)$.

are traditionally the most common form of DES therapy; they provide temporary symptomatic relief, but are unable to treat the vicious cycle of the underlying inflammatory mechanism. Treatment with topical anti-inflammatory agents, such as steroid, cyclosporine A, and tetracycline, has shown significant clinical improvement in patients with DES through a reduction in the expression of inflammatory cytokines and decreased activity of matrix metalloproteinases. ${ }^{16,17}$

Schirmer's test without anesthesia measures basal tear secretion and reflex tears from the main lacrimal gland, whose secretion is stimulated by an irritation such as filter paper. Schirmer's test after anesthesia application measures basal tear secretion. Basal tears are secreted and spread continuously by the eyes. In the present study, the results of Schirmer's test showed an increase in tear secretion without anesthesia, but not under anesthesia. This suggests that oral antioxidant supplementation can improve the function of the main lacrimal gland. Corneal fluorescein staining and TFBUT score improved after treatment with this oral antioxidant supplement, indicating that tear film stability increased and corneal epithelial cell damage decreased. Although we did not detect any improvement in the scores of

Table 8 Reactive oxygen species (chemiluminescence counts per 10 seconds) in tears without anesthesia given as mean \pm standard deviation

\begin{tabular}{|c|c|c|c|}
\hline Visit & $\begin{array}{l}\text { Placebo } \\
\text { group }\end{array}$ & $\begin{array}{l}\text { Treatment } \\
\text { group }\end{array}$ & $P$-value \\
\hline Visit I (day 0) & $|4.97 \pm| \mid .92$ & $18.49 \pm 12.30$ & 0.198 \\
\hline Visit 2 (week 4) & $15.81 \pm 16.08$ & $13.40 \pm 13.82$ & $0.46 \mathrm{I}$ \\
\hline Visit 3 (week 8) & $|4.94 \pm 9.0|$ & $|\mathrm{I} .14 \pm 1| .24$ & 0.113 \\
\hline Visit 4 (week I2) & $13.23 \pm 12.94$ & $15.77 \pm \mid 3.87$ & 0.391 \\
\hline Visit 5 (week I6) & $12.91 \pm 8.85$ & $13.37 \pm 10.42$ & 0.830 \\
\hline$P$-value & 0.754 & $0.024 *$ & \\
\hline
\end{tabular}

Notes: aLinear mixed model; ${ }^{\circ}$ repeated-measures analysis of variance. *Post hoc analysis (Bonferroni method) showed a significant difference between visit I and visit 3 $(P=0.014)$. 
Table 9 Reactive oxygen species (chemiluminescence counts per 10 seconds) in tears under $0.5 \%$ proparacaine anesthesia given as mean \pm standard deviation

\begin{tabular}{llll}
\hline Visit & $\begin{array}{l}\text { Placebo } \\
\text { group }\end{array}$ & $\begin{array}{l}\text { Treatment } \\
\text { group }\end{array}$ & P-value $^{\mathbf{a}}$ \\
\hline Visit I (day 0) & $8.15 \pm 10.35$ & $10.58 \pm 12.75$ & 0.340 \\
Visit 2 (week 4) & $8.19 \pm 7.60$ & $8.88 \pm 8.67$ & 0.701 \\
Visit 3 (week 8) & $9.94 \pm 11.28$ & $4.73 \pm 5.63$ & 0.008 \\
Visit 4 (week 12) & $6.35 \pm 8.80$ & $10.74 \pm 11.67$ & 0.056 \\
Visit 5 (week 16) & $8.71 \pm 6.94$ & $9.89 \pm 14.69$ & 0.645 \\
P-value $^{\text {b }}$ & 0.455 & 0.115 & \\
\hline
\end{tabular}

Notes: aLinear mixed model; brepeated-measures analysis of variance.

the five subjective symptoms, overall subjective impression of treatment effect was significantly positive in the treatment group.

Anti-SSA and anti-SSB antibodies are associated with Sjögren syndrome. The role of anti-SSA and anti-SSB antibodies is not yet understood; however, they are thought to potentially play a role in the immunopathogenesis of Sjögren syndrome. ${ }^{18,19}$ In the present study, the anti-SSA and anti-SSB antibody serum values were not significantly different between the two groups, or before and after treatment in either group. Therefore, antioxidant supplementation does not appear to have an effect on serum anti-SSA and anti-SSB antibodies.

The cornea is protected from oxidant damage by several primary scavengers in the tears, such as glutathione peroxidase, superoxide dismutase, and catalase. ${ }^{20}$ The protection of the cornea or conjunctival epithelial cells by this antioxidant mechanism may be limited in patients with DES. Several studies have shown that, in patients with DES, oxidative stress markers increase in tears and the conjunctival cells, and the levels of antioxidant enzyme decrease. ${ }^{21,22}$ Oxidative stress could potentially play a causative role in the inflammatory process and pathogenesis of dry eye. ${ }^{23}$

Essential fatty acids are necessary for health and must be obtained from a dietary source. Among these, omega-3 fatty acid is a natural anti-inflammatory agent that has been demonstrated to have beneficial effects as a dietary supplement in DES. ${ }^{24}$ In the present study, our antioxidant supplement that did not contain omega- 3 also reduced the activity of ROS in the tears, particularly in basal secretion tears. Increased generation of ROS-induced oxidative stress can trigger inflammasome activation and leads to elevated interleukin-1 $\beta$ secretion. ${ }^{25}$ This suggests ROS activity plays an important role in the development of DES. ${ }^{26,27}$ Increased ROS generation is associated with ocular surface epithelial damage and can induce lacrimal gland dysfunction. ${ }^{28}$ An imbalance between a radical scavenging system and ROS generation in the tears of patients with DES may cause ocular surface injury. ${ }^{29}$ Antioxidants can limit the harmful effect of ROS. ${ }^{30-32}$ Our findings were consistent with those of the aforementioned studies.

The oral antioxidant supplement investigated in the present study contained lycii fructus extract, astaxanthin, anthocyanosides, vitamins $\mathrm{C}$ and $\mathrm{E}$, and several herbal extracts. Lycii fructus can reduce ROS and oxidative damage and directly scavenges hydroxyl and superoxide radicals. ${ }^{33}$ Astaxanthin is a powerful antioxidant that can inhibit cell viability loss and ROS elevation. ${ }^{34}$ Vitamin $\mathrm{C}$ is a well-known cell protective natural antioxidant. Antioxidant vitamin $\mathrm{E}$ protects against retinal cell injury through a reduction in the formation of ROS. ${ }^{35}$ The seeds of Cassia tora (Cassiae semen) have been shown to possess strong antioxidant activity in lipid peroxidation. ${ }^{36,37}$ O. japonicus, a traditional Chinese medicine for treating cardiac disorders, is also an antioxidant and can repair oxidative damage in the brain. ${ }^{38,39}$ These herbal extracts can prevent oxidative stress damage and may be beneficial to patients with DES.

The pathophysiological mechanisms of hypertension are complex and involve multiple biological systems. Oxidative stress plays an important role in the pathogenesis of hypertension. It can result in an excessive generation of ROS, promoting inflammation and damage in endothelial cells. Antioxidant supplementation may have a protective effect in cardiovascular diseases by reducing ROS production. ${ }^{40,41}$ However, the findings on the effects of antioxidant

Table 10 Anti-SSA and anti-SSB given as mean \pm standard deviation

\begin{tabular}{|c|c|c|c|c|c|c|}
\hline \multirow[t]{2}{*}{ Visit } & \multicolumn{3}{|l|}{ Anti-SSA } & \multicolumn{3}{|l|}{ Anti-SSB } \\
\hline & $\begin{array}{l}\text { Placebo } \\
\text { group }\end{array}$ & $\begin{array}{l}\text { Treatment } \\
\text { group }\end{array}$ & $P$-value ${ }^{a}$ & $\begin{array}{l}\text { Placebo } \\
\text { group }\end{array}$ & $\begin{array}{l}\text { Treatment } \\
\text { group }\end{array}$ & $P$-value \\
\hline Visit I (day 0) & $50.98 \pm 145.45$ & $74.66 \pm 172.63$ & 0.632 & $50.44 \pm 172.84$ & $8.25 \pm 8.83$ & 0.255 \\
\hline Visit 3 (week 8) & $58.66 \pm 167.98$ & $47.60 \pm 116.69$ & 0.805 & $54.37 \pm 192.60$ & $6.54 \pm 6.90$ & 0.247 \\
\hline Visit 5 (week 16) & $49.21 \pm 142.65$ & II $8.97 \pm 265.67$ & 0.324 & $38.42 \pm I I 5.77$ & $9.53 \pm 18.53$ & 0.251 \\
\hline$P$-value ${ }^{b}$ & 0.975 & $0.54 I$ & & 0.943 & 0.770 & \\
\hline
\end{tabular}

Notes: ${ }^{a}$ Mann-Whitney U-test (two-sided); ${ }^{b}$ repeated-measures analysis of variance, the mean difference is significant at the 0.05 level. 
Table I I Subjective improvement of dry eye after supplementation

\begin{tabular}{llll}
\hline Symptom & $\begin{array}{l}\text { Placebo } \\
\text { group (\%) }\end{array}$ & $\begin{array}{l}\text { Treatment } \\
\text { group (\%) }\end{array}$ & P-value $^{\text {a }}$ \\
\hline Not improved & $15(65.2)$ & $6(30.0)$ & 0.021 \\
Improved & $8(34.8)$ & $14(70.0)$ & \\
\hline
\end{tabular}

Note: a Chi-square test (asymptomatic, two-sided).

supplementation on hypertension are inconsistent in the literature. The antioxidants administered in the present study, including astaxanthin, vitamin E, and Cassiae semen, have demonstrated antihypertensive effects through a reduction in oxidative stress. ${ }^{42,43}$ This may explain the lower diastolic blood pressure recorded in the treatment group after antioxidant supplementation.

Limitations of our study include the relatively small sample size and high rate of patient dropout. Furthermore, the severity between symptoms and signs of dry eye may be inconsistent in this study. Yeh et $\mathrm{al}^{44}$ demonstrated a low agreement between clinicians and patient assessments in dry eye severity, which may explain the inconsistency. Because the results of the differences between groups and before and after treatment are inconsistent in some parameters, it is hard to make a strong conclusion. Other drawback is that we did not evaluate participants' diet nor did we strictly control their diet. Many natural foods contain high antioxidants, such as grapes, blueberries, dark green vegetable, nuts, and fishes. These high antioxidant-rich foods might influence our results. However, our study still provides some information and trends about the treatment effect of oral antioxidant supplementations in patients with DES.

\section{Conclusion}

In the present study, overall patient assessments, objective measurements, and tear ROS results may indicate that this antioxidant supplement can improve general dry eye symptoms and increase the tear production and tear film stability through its anti-inflammatory effect in patients with DES. Since it only contains vegetable components, it is also suitable for vegetarians. Oral antioxidant supplementations may be utilized as an adjuvant therapy to conventional topical artificial tear treatment for patients with DES. Further large and long-term studies are needed to determine the benefits of oral antioxidant supplementations in patients with DES.

\section{Acknowledgments}

The authors would like to thank the participating patients and the staff of the Second Core Lab, Department of Medical Research, National Taiwan University Hospital.
This study was supported by the Acrobio Healthcare Inc., Taichung, Taiwan, and received grant MG-294 from the Department of Ophthalmology, National Taiwan University Hospital.

\section{Disclosure}

The authors report no conflicts of interest in this work.

\section{References}

1. Schaumberg DA, Sullivan DA, Buring JE, Dana MR. Prevalence of dry eye syndrome among US women. Am J Ophthalmol. 2003;136(2):318-326.

2. Lin PY, Tsai SY, Cheng CY, Liu JH, Chou P, Hsu WM. Prevalence of dry eye among an elderly Chinese population in Taiwan: the Shihpai Eye Study. Ophthalmology. 2003;110(6):1096-1101.

3. The definition and classification of dry eye disease: report of the definition and classification subcommittee of the International Dry Eye Workshop. Ocul Surf. 2007;5(2):75-92.

4. Flugfelder SC, Maskin SL, Anderson B, et al. A randomized, double masked, placebo-controlled, multicenter comparison of loteprednol etabonate ophthalmic suspension, $0.5 \%$, and placebo for treatment of keratoconjunctivitis sicca in patients with delayed tear clearance. Am J Ophthalmol. 2004;138(3):444-457.

5. Stevenson D, Tauber J, Reis BL. Efficacy and safety of cyclosporin A ophthalmic emulsion in the treatment of moderate-to-severe dry eye disease. A dose-ranging, randomized trial. Ophthalmology. 2000; 107(5):967-974.

6. Sommer A. Nutritional factors in corneal xerophthalmia and keratomalacia. Arch Ophthalmol. 1982;100(3):399-403.

7. Brown NA, Bron AJ, Harding JJ, et al. Nutrition supplements and the eye. Eye. 1998;12(Pt 1):127-133.

8. James MJ, Gibson RA, Cleland LG. Dietary polyunsaturated fatty acids and inflammatory mediator production. Am J Clin Nutr. 2000; 71(1 Suppl):343S-348S

9. Hodge W, Barnes D, Schachter HM, et al. Effects of omega-3 fatty acids on eye health. Evid Rep Technol Assess (Summ). 2005;117:1-6.

10. Macsai MS. The role of omega-3 dietary supplementation in blepharitis and meibomian gland dysfunction (an AOS thesis). Trans Am Ophthalmol Soc. 2008;106:336-356.

11. Sommer A. Effects of vitamin A deficiency on the ocular surface. Ophthalmology. 1983;90(6):592-600.

12. Patel S, Plaskow J, Ferrier C. The influence of vitamins and trace element supplements on the stability of the pre-corneal tear film. Acta Ophthalmol. 1993;71(6):825-829.

13. Dröge W. Free radicals in the physiological control of cell function. Physiol Rev. 2002;82(1):47-95.

14. Schmut O, Gruber E, el-Shabrawi Y, Faulborn J. Destruction of human tear proteins by ozone. Free Radic Biol Med. 1994;17(2):165-169.

15. Burton GW, Foster DO, Perly B, Slater TF, Smith IC, Ingold KU, Biological antioxidants. Philos Trans R Soc Lond B Biol Sci. 1985; 311(1152):565-578.

16. Marsh P, Pflugfelder SC. Topical nonpreserved methylprednisolone therapy for keratoconjunctivitis sicca in Sjogren syndrome. Ophthalmology. 1999;106(4):811-816.

17. Solomon A, Rosenblatt M, Li DQ, et al. Doxycycline inhibition of interleukin-1 in the corneal epithelium. Invest Ophthalmol Vis Sci. 2000; 41(9):2544-2557.

18. Provost TT. Anti-Ro(SSA) and anti-La(SSB) antibodies in lupus erythematosus and Sjögren's syndrome. Keio J Med. 1991;40(2):72-77.

19. Franceschini F, Cavazzana I. Anti-Ro/SSA and La/SSB antibodies. Autoimmunity. 2005;38(1):55-63.

20. Cejková J, Stípek S, Crkovská J, Ardan T. Changes of superoxide dismutase, catalase and glutathione peroxidase in the corneal epithelium after UVB rays. Histochemical and biochemical study. Histol Histopathol. 2000;15(4):1043-1050. 
21. Wakamatsu TH, Dogru M, Matsumoto Y, et al. Evaluation of lipid oxidative stress status in Sjögren syndrome patients. Invest Ophthalmol Vis Sci. 2013;54(1):201-210.

22. Norheim KB, Jonsson G, Harboe E, Hanasand M, Gøransson L, Omdal R. Oxidative stress, as measured by protein oxidation, is increased in primary Sjøgren's syndrome. Free Radic Res. 2012;46(2):141-146.

23. Augustin AJ, Spitznas M, Kaviani N, et al. Oxidative reactions in the tear fluid of patients suffering from dry eyes. Graefes Arch Clin Exp Ophthalmol. 1995;233(11):694-698.

24. Rand AL, Asbell PA. Nutritional supplements for dry eye syndrome. Curr Opin Ophthalmol. 2011;22(4):279-282.

25. Zheng Q, Ren Y, Reinach PS, et al. Reactive oxygen species activated NLRP3 inflammasomes initiate inflammation in hyperosmolarity stressed human corneal epithelial cells and environment-induced dry eye patients. Exp Eye Res. 2015;134(5):133-140.

26. Nakamura S, Shibuya M, Nakashima H, et al. Involvement of oxidative stress on corneal epithelial alterations in a blink-suppressed dry eye. Invest Ophthalmol Vis Sci. 2007;48(4):1552-1558.

27. Wakamatsu TH, Dogru M, Tsubota K. Tearful relations: oxidative stress, inflammation and eye diseases. Arq Bras Oftalmol. 2008;71(Suppl 6): $72-79$.

28. Kojima T, Wakamatsu TH, Dogru M, et al. Age-related dysfunction of the lacrimal gland and oxidative stress: evidence from the $\mathrm{Cu}, \mathrm{Zn}$ superoxide dismutase-1 (Sod1) knockout mice. Am J Pathol. 2012; 180(5):1879-1896.

29. Cejková J, Stípek S, Crkovská J, et al. UV rays, the prooxidant/antioxidant imbalance in the cornea and oxidative eye damage. Physiol Res. 2004;53(1):1-10.

30. Stoddard AR, Koetje LR, Mitchell AK, Schotanus MP, Ubels JL. Bioavailability of antioxidants applied to stratified human corneal epithelial cells. J Ocul Pharmacol Ther. 2013;29(7):681-687.

31. Cavet ME, Harrington KL, Vollmer TR, Ward KW, Zhang JZ. Antiinflammatory and anti-oxidative effects of the green tea polyphenol epigallocatechin gallate in human corneal epithelial cells. Mol Vis. 2011;17: 533-542.

32. Morganti P, Fabrizi G, Bruno C. Protective effects of oral antioxidants on skin and eye function. Skin Med. 2004;3(6):310-316.

33. Feng Z, Jia H, Li X, et al. A milk-based wolfberry preparation prevents prenatal stress-induced cognitive impairment of offspring rats, and inhibits oxidative damage and mitochondrial dysfunction in vitro. Neurochem Res. 2010;35(5):702-711.
34. Lee DH, Kim CS, Lee YJ. Astaxanthin protects against PTP/MPP+induced mitochondrial dysfunction and ROS production in vivo and in vitro. Food Chem Toxicol. 2011;49(1):271-280.

35. Rego AC, Santos MS, Oliveira CR. Influence of the antioxidants vitamin $\mathrm{E}$ and idebenone on retinal cell injury mediated by chemical ischemia, hypoglycemia, or oxidative stress. Free Radic Biol Med. 1999; 26(11-12):1405-1417.

36. Kim SY, Kim JH, Kim SK, Oh MJ, Jung MY. Antioxidant activities of selected oriental herb extracts. J Am Oil Chem Soc. 1994;71(6): 633-640.

37. Yen GC, Chen HW, Duh, PD. Extraction and identification of an antioxidative component from Jue Ming Zi (Cassia tora L.). J Agric Food Chem. 1998;46:820-824.

38. Konishi T. Brain oxidative stress as basic target of antioxidant traditional oriental medicines. Neurochem Res. 2009;34(4):711-716.

39. Wu L, Ding XP, Zhu DN, et al. Study on the radical scavengers in the traditional Chinese medicine formula shengmai san by HPLC-DAD coupled with chemiluminescence (CL) and ESI-MS/MS. J Pharm Biomed Anal. 2010;52(4):438-445.

40. Kizhakekuttu TJ, Widlansky ME. Natural antioxidants and hypertension: promise and challenges. Cardiovasc Ther. 2010;28(4):e20-e32.

41. Sasaki Y, Kobara N, Higashino S, Giddings JC, Yamamoto J. Astaxanthin inhibits thrombosis in cerebral vessels of stroke-prone spontaneously hypertensive rats. Nutr Res. 2011;31(10):784-789.

42. Monroy-Ruiz J, Sevilla MÁ, Carrón R, Montero MJ. Astaxanthinenriched-diet reduces blood pressure and improves cardiovascular parameters in spontaneously hypertensive rats. Pharmacol Res. 2011; 63(1):44-50.

43. Koo A, Chan WS, Li KM. A possible reflex mechanism of hypotensive action of extract from Cassia tora seeds. Am J Chin Med (Gard City N Y). 1976;4(3):249-255.

44. Yeh PT, Chien HC, Ng K, et al. Concordance between patient and clinician assessment of dry eye severity and treatment response in Taiwan. Cornea. 2015;34(5):500-505.
Clinical Ophthalmology

\section{Publish your work in this journal}

Clinical Ophthalmology is an international, peer-reviewed journal covering all subspecialties within ophthalmology. Key topics include: Optometry; Visual science; Pharmacology and drug therapy in eye diseases; Basic Sciences; Primary and Secondary eye care; Patient Safety and Quality of Care Improvements. This journal is indexed on Submit your manuscript here: http://www.dovepress.com/clinical-ophthalmology-journal

\section{Dovepress}

PubMed Central and CAS, and is the official journal of The Society of Clinical Ophthalmology (SCO). The manuscript management system is completely online and includes a very quick and fair peer-review system, which is all easy to use. Visit http://www.dovepress.com/ testimonials.php to read real quotes from published authors. 